\title{
PEMBERDAYAAN LINGKUNGAN PADA MASYARAKAT SADAR GIZI UNTUK KETAHANAN PANGAN DESA
}

\author{
Vivien Novarina A. Kasim*1 ${ }^{1}$, Nirwanto K. Rahim ${ }^{2}$ \\ ${ }^{1}$ Fakultas Kedokteran, Universitas Negeri Gorontalo, \\ ${ }^{2}$ Keperawatan, Fakultas Olahraga dan Kesehatan, Universitas Negeri Gorontalo \\ Email : ${ }^{1}$ viviennovarina@ung.ac.id ${ }_{2}^{2}$ rahim.nirwanto@yahoo.co.id
}

\begin{abstract}
ABSTRAK
Status gizi di Kabupaten Bone Bolango berdasarkan data survey pemantauan status gizi (PSG) Provinsi Gorontalo, termasuk dalam kategori moderat (6,6\%). Desa Tulabolo Barat yang berada di kecamatan Suwawa Timur, merupakan lokasi terpilih untuk kegiatan pengabdian ini karena merupakan salah satu lokasi yang rawan dengan masalah gizi. Hal ini ditinjau dari skor persen standar identifikasi kecamatan rawan gizi BB/PB yang ada di Kabupaten Bone Bolango. Desa Tulabolo, sebagian besar merupakan areal pertanian dimana hasil lahan terbanyak berupa pisang, jagung, dan lombok dan mayoritas penduduknya adalah petani. Pemberdayaan lingkungan berbasis masyarakat Sadar Gizi meliputi inventarisir potensi desa, pelatihan kader gizi dan pembentukan lembaga konservasi lingkungan desa, percontohan Kawasan Rumah Pangan Lestari (KRPL), ekonomi kreatif; pembuatan bros kulit jagung, dan stik pisang. Kegiatan pengabdian yang dilaksanakan selama 2 bulan dapat meningkatkan pemberdayaan lingkungan yang berpotensi untuk peningkatan ketahanan pangan desa, namun demikian tetap diperlukannya perhatian khusus dari pemerintah setempat untuk medorong dan memotivasi agar masyarkat dan kader gizi lebih aktif dalam melakukan pengembangan potensi desa untuk pemenuhan ketahanan pangan masyakarat.
\end{abstract}

Keywords: Sadar gizi, Potensi desa, Kawasan rumah pangan lestari, Status gizi 


\section{PENDAHULUAN}

Dalam rangka upaya pemenuhan kebutuhan pangan masyarakat, faktor ketersediaan pangan merupakan hal yang penting, khususnya dalam pemenuhan kebutuhan makanan yang merupakan kebutuhan dasar manusia. Peningkatan jumlah penduduk Indonesia signifikan berpengaruh terhadap pemenuhan kebutuhan dan ketersediaan pangan yang cukup. Oleh karena itu ketahnan pangan harus dilakukan diperhatikan dengan baik secara terus-menerus. Berdasarkan Rencana Pembangunan Jangka Menengah Nasional (RPJMN) tahun 2015-2019, pembangunan ketahanan pangan merupakan hal prioritas yang mencakup pemantapan ketahanan pangan melalui program peningkatan produksi pangan, menstabilkan harga pangan, memperbaiki kualitas konsumsi pangan dan gizi masyarakat, mengatasi gangguan terhadap ketahanan pangan serta meningkatkan kesejahteraan pelaku usaha pangan yang bertujuan untuk menuju kemandirian pangan ${ }^{1}$. Langkah-langkah tersebut dilakukan bertujuan juga sebagai salah satu upaya meningkatkan pertumbuhan ekonomi serta menurunkan taraf kemiskinan masyarakat.

Isu ketahanan pangan menjadi pembahasan utama dalam upaya penyelesaian permasalahan kasus gizi buruk karena ketahanan pangan yang terkelola dengan baik secara tidak langsung meningkatkan status gizi masyarakat. Jika ketahanan pangan baik maka kebutuhan pangan akan tepenuhi, kelangkaan makanan pokok dapat teratasi sehingga pemenuhan zat gizi makro akan tercukupi dan status gizi akan mengalami perbaikan. Ketahanan pangan berhubungan erat dengan pembangunan khususnya dari segi pertanian ${ }^{2}$. Ketersediaan pangan sangat ditentukan oleh produksi pangan dalam negeri serta ekspor dan impor pangan. Hal ini akan mempengaruhi kondisi ketahanan pangan suatu negara/wilayah secara nasional. Adapun pada tingkat rumah tangga, ketahanan pangan ditentukan oleh daya beli dan sifat konsumtif dari masing-masing individu dan keluarga terhadap pangan tersebut ${ }^{3}$.

Pangan yang bergizi, beragam, mutu yang baik, aman, cukup, merata dan terjangkau oleh kemampuan daya beli keluarga pada tingakat rumah tangga, dapat dijadikan sebagai indikator bahwa ketersediaan pangan di tingkat rumah tangga baik. Apabila beberapa hal tersebut tidak dapat terpenuhi maka akan sangat mempengaruhi ketahanan pangan tingkat rumah tangga. Hal ini secara tidak langsung mempengaruhi status gizi dari individu masingmasing anggota keluarga. Status gizi yang baik mempengaruhi pertumbuhan, perkembangan dan aktifitas tubuh. Mempengaruhi kecerdasan sekaligus prestasi dan kualitas kerja anggota 
keluarga dan juga terutama dari segi kesehatan akan terjaga dan terpelihara, proses penyembuhan penyakit serta mekanisme fisiologis yang normal selalu terjaga. Olehnya demikian, jika ketersediaan pangan tercukupi pada tingkat rumah tangga, akan mempengaruhi sifat konsumsi makanan semua anggota keluarga. Jika sifat konsumsi anggota keluarga baik yakni sesuai dengan gizi seimbang maka status gizi yang baik akan tercapai ${ }^{4}$. Jika ketersediaan pangan dalam tingkat rumah tangga kurang baik, maka akan terjadi kelaparan sehingga status gizi bisa mengarah ke status gizi kurung bahkan bisa status gizi buruk (Marasmus/Kwasiorkor). Ketidakcukupan dari ketersediaan pangan akan mengakibatkan rasa "tidak enak" dan sakit akibat kurang atau tidak makan, baik yang disengaja maupun yang tidak disengaja diluar kehendak dan terjadi berulang-ulang, serta dalam jangka waktu tertentu menyebabkan penurunan berat badan dan gangguan kesehatan.

Data Riset Kesehatan Dasar (Riskesdas) 2018 menunjukan, bahwa masih terdapat 95,5\% penduduk $\geq 5$ tahun yang kurang dalam mengkonsumsi buah atau sayur (meningkat dibandngkan data Riskesdas 2013). Walaupun jika dilihat dari data status gizi, gizi kurang $(13,8 \%)$ dan gizi buruk $(3,9 \%)$ mengalami penurunan sedikit dibanding sebelumnya ${ }^{5}$. Di dukung juga dengan Data Global Nutrition Report yang menyatakan bahwa Indonesia termasuk negara yang sudah memiliki progress dalam penyelesaian permasalahan stunting dan gizi kurang/buruk walaupun permasalahan gizi lainnya seperti kasus anemia pada ibu hamil, obestas dan diabetes melitus masih belum mengalami kemajuan dalam penanganannya ${ }^{6}$. Hal ini masih sama dengan situasi sebelumnya bahwa di Indonesia memiliki masalah gizi yang kompleks, karena tidak hanya berhubungan dengan kesehatan saja namun juga ekonomi, sosial, budaya, pendidikan dan lingkungan. Peran dari ketersediaan pangan dalam rumah tangga secara tidak langsung sangat mempengaruhi permasalahan gizi yang ada ${ }^{7}$. Ketahanan pangan yang rendah serta daya beli masyarakat yang rendah pula merupakan salah satu hal yang menjadi penyebab dari ketersediaan pangan yang rendah pada tingkat rumah tangga.

Masalah status gizi masih menjadi masalah kesehatan masyarakat utamanya di Provinsi Gorontalo. Menurut Riskesdas 2018, proporsi status gizi kurang dan gizi buruk balita masih masuk dalam 3 besar setelah proporsi NTT (29,5\%), proporsi stunting menurun dibanding hasil Riskesdas 2013, proporsi konsumsi buah/sayur lebih rendah dibandingkan dengan proporsi penduduk Indonesia $(95,5 \%)^{5}$. Beberapa indikator gizi diatas mencerminkan status kesehatan masyarakat khususnya masyarakat Gorontalo. Upaya-upaya dalam rangka peningkatan status 
gizi masyarakat perlu dilakukan lebih implementasi lagi, guna permasalahan gizi kurang dan gizi buruk dapat teratasi dengan lebih baik dibandingkan sebelumnya. Salah satu upaya yang kami lakukan adalah melalui kegiatan pengabdian masyarakat berbasis pada pelayanan dan pendampingan mahasiswa, ditujukan untuk meningkatkan derajat kesehatan masyarakat pada umumnya dan perbaikan status gizi pada khususnya. Upaya peningkatan derajat kesehatan masyarakat dapat dilakukan dengan berbagai cara salah satunya yakni Program berbasis lingkungan. Lingkungan bersifat esensial bagi kesehatan manusia. Pada dasarnya lingkungan yang berada dalam lingkup manusia sangat berperan dalam kesehatan, dimana sebagian besar pangan masyarakat bersumber dari lingkungan.

Berdasarkan data survey pemantauan status gizi (PSG) Provinsi Gorontalo tahun 2013 Kabupaten Bone Bolango Masuk dalam kategori moderat dengan presentase sebesar $(6,6 \%)^{8}$. Kabupaten bone bolango tahun 2013 terdapat beberapa lokasi/kecamatan yang merupakan lokasi yang bebas masalah gizi dan juga merupakan rawan dengan masalah gizi ditinjau dari skor persen standar identifikasi kecamatan rawan gizi $\mathrm{BB} / \mathrm{PB}^{9,10}$. Sebagian besar wilayah merupakan areal pertanian dimana hasil lahan terbanyak berupa pisang, jagung, dan Lombok dengan penduduk mayoritas petani bekerja sebagai petani, ojek, dan wiraswasta dengan jumlah penduduk mencapai 509 Jiwa. Berdasarkan latar belakang di atas, maka perlu dilakukan suatu pengabdian masyarakat yang bertujuan untuk meningkatkan status gizi masyarakat melalui pemanfaatan lahan pekarangan atau lingkungan rumah demi terwujdunya suatu ketersediaan pangan yang baik sehingga ketahanan pangan dapat terjaga.

\section{METODE}

Kegiatan pengabdian masyarakat ini dirangkaikan dengan kuliah kerja nyata mahasiswa. Jadi dosen dan mahasiswa berkolaborasi memberikan pelayanan dan pengabdian kepada masyarakat yang telah terdata. Mahasiswa akan dibagi dalam kelompok dan membina klien kelolaan dengan kasus-kasus kesehatan yang berbeda. Dalam pembinaan kelompok masyarakat guna peningkatan masyarakat sadar gizi, mahasiswa akan melakukan inventarisir potensi desa, pelatihan kader gizi dan pembentukan lembaga konservasi lingkungan desa, percontohan Kawasan Rumah Pangan Lestari (KRPL), ekonomi kreatif; pembuatan bros kulit jagung, dan stik pisang. Yang pada akhirnya melaksanakan pertemuan masyarakat desa dan pemerintah desa mendorong penyusunan strategi dalam menjaga dan mengelola kawasan 
konservasi sadar gizi dengan memasukkan serta meneruskan program-program sadar gizi ini pada program BUMDES.

\section{HASIL DAN PEMBAHASAN}

Inventarisir Potensi Desa

Intenvarisir potensi desa dilakukan dengan cara mengobservasi, mendata aspek yang terkait dengan konservasi dan pangan , isu dan permasalahan masyarakat serta merencanakan kerangka pikirsolusi permasalahan berdasarkan hasil observasi. Observasi dilakukan oleh mahasiswa KKN Kebangsaan desa Tulabolo Barat dengan menggunakan metode langsung serta wawancara dengan warga yang rumah/kebunnya dilewat/ dikunjungi. Hasil observasi memberikan info tentang desa Tulabolo Barat antara lain : Desa Tulabolo barat dipimpin oleh seorang kepala desa bernama ibu Herawati Mukodompit dan dibantu oleh seorang serkertaris desa (Sekdes) bermana Ferdi Ar-Raud. Desa Tulabolo Barat mempunyai Jumlah Penduduk 485 Jiwa (262 laki-laki dan 223 Perempuan), terdiri dari 135 kepala keluarga. Penduduk ini tersebar dalam 3 wilayah dusun yaitu dusun bulabo daa, bulabo diti dan dudamu.

Desa Tulabolo Barat memiliki luas lahan pertanian yang cukup luas dimana Penggunaan Tanah di Desa Tulabolo Barat sebagian besar diperuntukan untuk Tanah Pertanian,Perkebunan,dan Holtikultura berupa Jagung,cabai rawit,sayur-sayuran dan pisang sedangkan sisanya untuk pemukiman, bangunan fasilitas umum dan hutan produksi. Masalah utama yang dikeluhkan warga desa tulabolo barat adalah masalah hama yang mengganggu hasil pertanian yang menyebabkan kerugian pada hasil pertanian warga. Sedangkan masalah lainnya adanya banjir yang mengganggu lahan warga

Pelatihan Kader Gizi dan Pembentukan Lembaga Konservasi Lingkungan

Pembentukan lembaga konservasi dilakukan bersamaan dengan sosialisan KRPL (Kawasan Rumah Pangan Lesatari) dan pelatihan Kader Gizi. Pelatihan Kader Gizi ini diikuti oleh 18 orang warga desa tulabolo barat. Pembentukan lembaga konservasi ini dilakukan oleh mahasiswa KKN Kebangsaan. Masyarakat sangat antusis pada materi yang disampaikan yang ditandai dengan banyaknya pertanyaan masyarakat terkait KRPL dan pangan gizi KRPL. Setelah sosialisai dan pelatihan dilanjutkan dengan pemilihan ketua lembaga konservasi, pemilihan ini dipimpin oleh koordinator desa Irham Abdika, pemilihan dilakukan oleh warga kemudian disetujui oleh calon ketua konservasi desa. Setelah beberapa nama yang diajukan 
oleh warga maka terpilihlah ibu Olis Patalangi sebangai Ketua Konservasi lingkungan Desa Tulabolo Barat.

Percontohan Kawasan Rumah Pangan Lestari

KRPL adalah rumah penduduk yang mengusahakan pekarangan secara intensif untuk dimanfaatkan dengan berbagai sumberdaya lokal secara bijaksana yang menjamin kesinambungan penyediaan bahan pangan rumah tangga yang berkualitas dan beragam.Terdapatnya percontohan Kawasan Rumah Pangan Lestari (KRPL) di Desa Tulabolo Barat. Dan telah di ikuti oleh beberapa warga di beberapa dusun yang ada di Desa Tulabolo Barat.

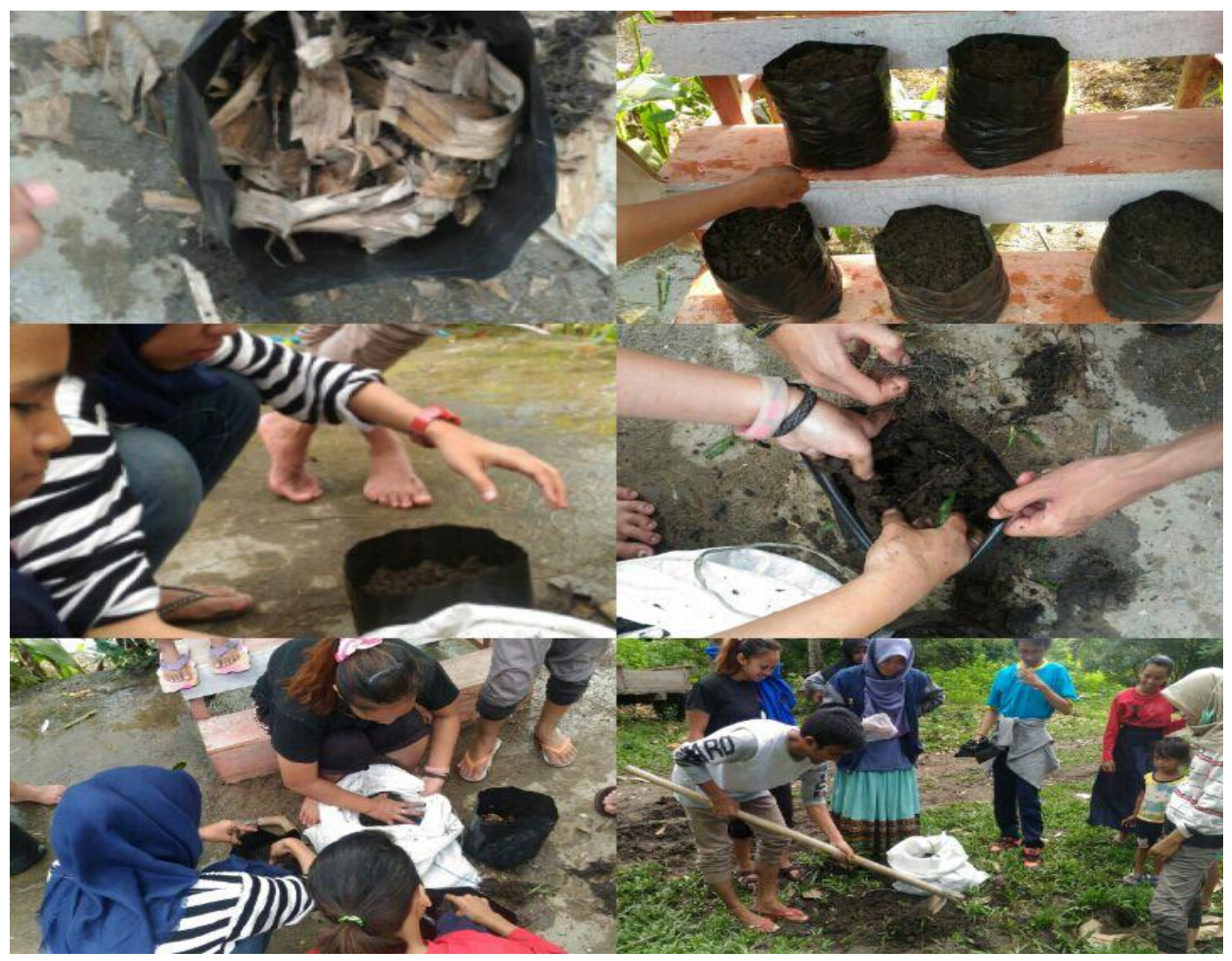

Gambar 1. Proses Pembuatan Kawasan Rumah Pangan Lestari 

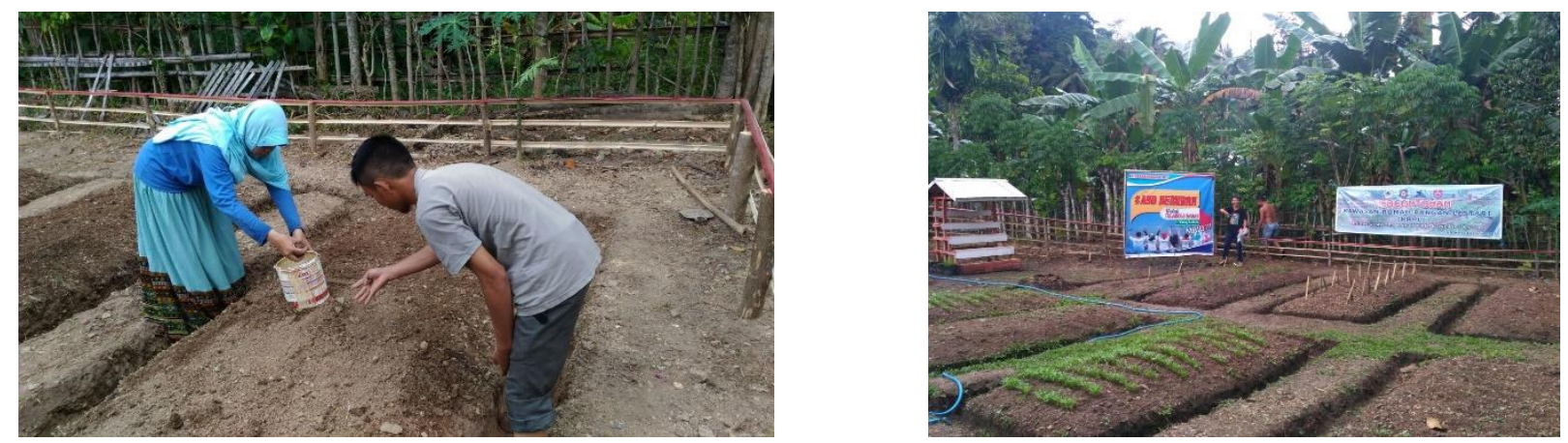

Gambar 2. Contoh Kawasan Rumah Pangan Lestari

Pelayanan Kesehatan, Pemeriksaan dan Pengobatan Gratis

Memberikan Pelayanan Kesehatan pada masyarakat berupa tensi, pengecekan gula darah, asam urat, dan kolesterol serta masalah terkait kesehatan masyarakat desa Tulabolo Barat. Pemberian pelayanan kesehatan pada masyarakat yang datang ke posko, mendatangi rumah warga (Home Visit) dan mendatangi warga yang sakit, melakukan pengecheckan gula darah, asam urat atau kolestrol dan pengukuran tekanan darah kemudian warga diberi obat sesuai keluhan warga yang datang.

Ekonomi Kreatif ; Pembuatan Bros Kulit Jagung, Pembuatan Stick Pisang

Penyuluhan pembuatan bros kulit jagung oleh mahasiswa KKN Kebangsaan kepada ibu-ibu PKK desa Tulabolo Barat yang nantinya pembuatan bros kulit jagung ini dijadikan salah satu program PKK, sehingga dapat terus dilanjutkan dan dikembangkan untuk meningkatkan ekonomi masyarakat Tulabolo Barat.

Selain pembuatan bros kulit jagung, untuk meningkatkan perekonomian masyarakat yakni pembuatan produk stik pisang, dimana yang nantinya dapat dipasarkan dengan bekerja sama dengan BUMDES (Badan Usaha Milik Desa) sehingga produk ini menjadi produk andalah desa Tulabolo Barat.
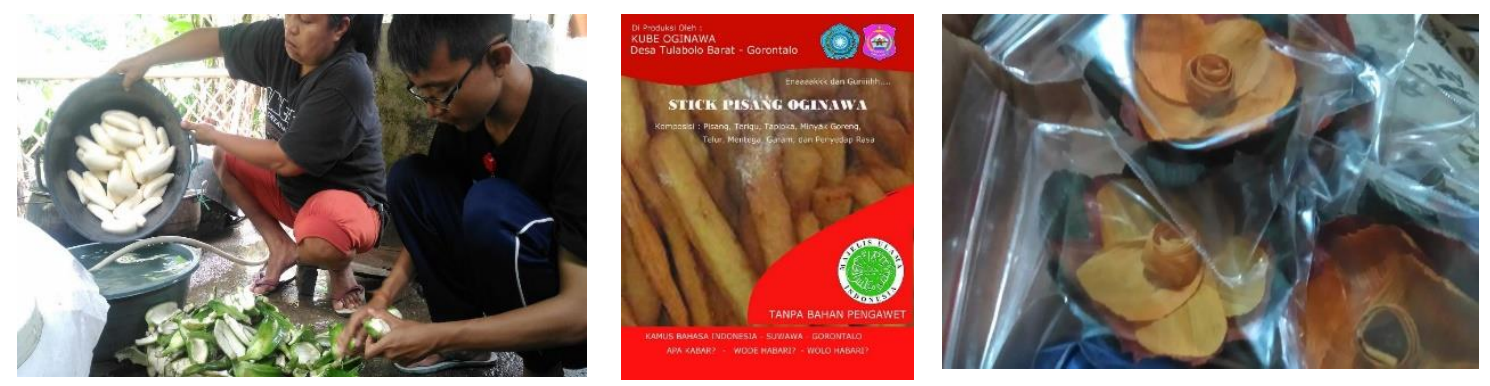

Gambar 3. Ekonomi Kreatif Pembuatan Stik Pisang dan Bros Jagung 
KKNK Mengajar ; Penyuluhan Hidup Bersih dan Sehat, Pertolongan Pertama,Yuk menabung dan Lingkungan Sehat

Penyuluhan dilakukan oleh Mahasiswa KKN Kebangsaan dengan motode menjelaskan menggunakan power point dan simulasi lansung oleh siswa satu persatu . Siswa mengerti dan paham 6 langkah mencuci tangan yang baik dan benar serta mengerti manfaat dan waktu dari cuci tangan, Siswa mengerti dan paham tentang pertolongan pertama seperti pertolongan pada luka bakar, demam, mimisan, luka tusuk, pingan, gigitan ular dan cara merawat luka. Siswa mengerti dan paham tentang Pentingnya menabung dan menghargai nilai mata uang. Siswa mengerti dan paham tentang Pentingnya menjaga lingkungan sekitar.

Pelaksanaan program KKN kebangsaan dilaksanakan selama 45 hari, dengan beberapa program kerja dilakukan dimulai dengan menginvrntarisir potensi. Observasi ini dilakukan oleh mahasiswa KKN Kebangsaan dengan kepala desa dan dibantu oleh sekretaris desa dimana diketahui jumlah penduduk 485 Jiwa diman 262 orang laki-laki dan 223 perempuan, terdiri dari 135 kepala keluarga, didaptkan juga luas lahan pertanian yang cukup luas yang diperuntukkan untuk tanah pertanian, perkebunan, holtikultutra berupa jagungm cabai rawit, sayur-sayuran, dan pisang, sedangkan sisanya untuk pemukiman, bangunan, fasilitas umum dan hutan produksi. Selanjutnya diadakn lokakarya awal porgram KKN Kebangsaan, kegiatan ini dilakukan di Kantor Desa Tulabolo Barat tujuannya untuk memberikan informasi mengenai kegiatan yang akan dilaksanakan oleh pesera KKN. Pelatihan kader gizi dan pembentukan lembaga konservasi lingkungan desa, pembentukkan lembaga ini dilakukan bersamaan sosialisasi KRPL (Kawasan Rumah Pangan Lestari) dan Pelatihan kasder giz, sehingga dalam pemilihan ini terpilihlah Ibu Olis Patalngi sebagai Ketua Konservasi Lingkungan Desa. Kegiatan percontohan Kawasan Rumah Pangan Lestari (KRPL) dan telah diikuti oleh beberapa warga di beberapa dusun. Pada sela-sela kegiatan sehari-hari melakukan pelayanan kesehatan pada masyarakat yang mendatangi ke posko, melakukan home visit pada warga yang sakit, melakukan pengecekan gula darah, asam urat ata kolesterol dan pengukuran tekanan darah, kemudian warga di beri obat sesuai keluhan warga yang datang. Untuk kegiatan ekonomi kreatif bersama warga dilakukan pembuatan bros jagung dan dilakukan pembuatan stik pisang untuk meningkatkan perekonomian masyarakat, dimana kegiatan ini bekerja sama dengan BUMDES( Badan Usaha Milik Desa), dimana bertujuan untuk menjadikan produk olahan ini sebagai produk andalan masyarakat. Kegiatan KKNK Mengajar materinya terkait penyuluhan hidup 
bersih dan sehat, pertolongan pertama, yuk menabung dan lingkungan sehat, hal ini dilakukan untuk meningkatkan kesedaran terkait pentingnya cuci tangan yang baik dan benar, memberikan penyuluhan terkait pertolonga pertama pada kecelakaan, pentingnya menabung, dan menghargai nilai mata uang, menjaga lingkungan sekitar.

\section{KESIMPULAN}

Kegiatan pengabdian masyarakat yang dilakukan melalui program KKN Kebangsaan menujukkan bahwa penerapan intervensi yang dilakukan dapat meningkatkan pemberdayaan lingkungan oleh masyarakat untuk peningkatan ketahanan pangan desa. Namun demikian tetap diperlukannya perhatian khusus dari pemerintah setempat untuk medorong dan memotivasi agar masyarkat dan kader gizi lebih aktif dalam melakukan pengembangan potensi desa untuk pemenuhan ketahanan pangan masyakarat. .

\section{DAFTAR PUSTAKA}

Badan Ketahanan Pangan. 2015. Rencana Strategis Badan Ketahanan Pangan Tahun 20152019. Badan Ketahanan Pangan Kementrian Pertanian. Jakarta Selatan. http://bkp.pertanian.go.id/blog/post/renstra-2015-2019

Darawanto, Dwijono. 2005. Ketahanan Pangan Berbasis Produksi dan Kesejahteraan Petani. Vol. 12 No 2 Ilmu Petanian. Fakultas Pertanian UGM, Yogyakarta. http://ilib.ugm.ac.id/jurnal/detail.php?dataId=7527

Purwaningsih, Yunastiti. 2008. Ketahanan Pangan ; Situasi Permaslahan, Kebijakan dan Pemberdayaan Masyarakat. Vol 9, No 1. Fakultas Ekonomi, Surakarta. https://www.researchgate.net/publication/314098698_KETAHANAN_PANGAN_SITUASI PERMASALAHAN_KEBIJAKAN_DAN_PEMBERDAYAAN_MASYARAKAT

Rachman, Handewi. 2002. Ketahanan Pangan : Konsep, Pengukuran dan Strategi. FAE Volume 20 No. 1. Jakarta.

http://ejurnal.litbang.pertanian.go.id/index.php/fae/article/view/4280

Kementrian Kesehatan, 2018. Riset Kesehatan Dasar (Riskesdas).

Global Nutrition Report, 2020. Indonesia : The Global Burden of Malnutrition at a Glance. https://globalnutritionreport.org/resources/nutrition-profiles/

Almatsier S, Soetardjo S, Soekatri M, 2011. Gizi Seimbang Dalam Daur Kehidupan. Jakarta: Gramedia Pustaka Utama. https://ebooks.gramedia.com/id/buku/gizi-seimbang-dalam-daurkehidupan

Dinas Kesehatan Provinsi Gorontalo. 2014. Profil Kesehatan Provisni Gorontalo. Provinsi Gorontalo. https://dinkes.gorontaloprov.go.id/profil-kesehatan/ 
Dinas Kesehatan Bone Bolango. 2014. Profil Kesehatan Bone Bolango Tahun Kabupaten Bone Bolango. Kabupaten Bone Bolango. https://adoc.pub/profil-kesehatan-kabupaten-bonebolango-tahun-2014.html

Pemerintah Kabupaten Bone Bolango. 2011. Rencana Pembangunan Jangka Menengah Daerah (RPJMD) Tahun 2011-2015. https://www.scribd.com/doc/175371005/Rpjmd-Bone-Bolango200-2015

Pemerintah Kabupaten Bone Bolango. Buku Putih Sanitasi (BPS) Kabuaten Bone Bolango Tahun 2013. Pemerintah Kabupaten Bone Bolango. https://bonebolangokab.bps.go.id/ 